\title{
Characterization of a Membrane Interface for Analysis of Air Samples Using Time-of-flight Mass Spectrometry
}

\author{
Yu-Mi Jang, Jun-Sik Oh, Chang Joon Park, ${ }^{\dagger}$ Sang Sik Yang, ${ }^{\ddagger}$ and Kwang-Woo Jung ${ }^{*}$
}

\author{
Department of Chemistry and Institute of Nanoscience \& Tech., Wonkwang University, Iksan, Chonbuk 570-749, Korea \\ ${ }^{*}$ E-mail: kwjung@wku.ac.kr \\ ${ }^{\dagger}$ Korea Research Institute of Standards and Science, 1 Doryong-Dong, Yeseong-Gu, Daejeon 305-340, Korea \\ ${ }^{\sharp}$ Division of Electrical \& Computer Engineering, Ajou University, Suwon 443-749, Korea \\ Received June 27, 2010, Accepted August 9, 2010
}

\begin{abstract}
In the present study, we constructed a membrane inlet assembly for selective permeation of volatile airborne organic compounds for subsequent analysis by time-of-flight mass spectrometry. The time-dependent diffusion of analytes through a $75 \mu \mathrm{m}$ thick polydimethylsiloxane membrane was measured by monitoring the ion signal after a step change in the sample concentration. The results fit well to a non-steady-state permeation equation. The diffusion coefficient, response time, and sensitivity were determined experimentally for a range of polar (halogenated) and nonpolar (aromatic) compounds. We found that the response times for several volatile organic compounds were greatly influenced by the alkyl chain length as well as the size of the substituted halogen atoms. The detection limits for benzene, ethylbenzene, and 2-propanol were $0.2 \mathrm{ppm}, 0.1 \mathrm{ppm}$, and $3.0 \mathrm{ppm}$ by volume, respectively, with a linear dynamic range greater than three orders of magnitude. These results indicate that the membrane inlet/time-of-flight mass spectrometry technique will be useful for a wide range of applications, particularly for in situ environmental monitoring.
\end{abstract}

Key Words: Membrane inlet, Polydimethylsiloxane (PDMS), Time-of-flight mass spectrometry, Diffusion coefficient

\section{Introduction}

Over the last few decades, semipermeable membranes have found applications in a variety of separation processes, such as desalination, dialysis, ultrafiltration, gas separation, dehumidification, osmosis, reverse osmosis, and electrodialysis. ${ }^{1-3}$ In these applications, the membrane primarily functions as a separator of two bulk phases, and controls mass transfer between the phases. An important advantage of membrane separation techniques is that they allow the simultaneous extraction and enrichment of analytes, and typically facilitate selective extraction at trace levels while consuming only small quantities of solvent. Consequently, a sample matrix may be brought into continuous contact, providing a means for continuous, automated, real-time processing with an on-line interface to analytical instruments. ${ }^{4}$

Recent work on membrane introduction mass spectrometry (MIMS) has shown that it is one of the simplest, most efficient, and sensitive techniques for real-time on-site analysis of volatile organic compounds (VOCs) and other analytes present in air and water matrices. ${ }^{5-8}$ MIMS benefits from the selective transport of analytes through a semipermeable membrane, which is usually a hydrophobic silicone polymer. Silicone is useful because it allows selective permeation of volatile organic analytes, while the primary components of air are mostly blocked. This difference in permeability is important because it facilitates direct monitoring (without sample preparation) of volatile analytes over a wide range of concentrations in complex gaseous mixtures. The analytes are thus transferred without extraction or pretreatment steps from the sample directly into the ion source of a mass spectrometer, in which they are ioniz- ed and detected normally at trace levels. ${ }^{9-11}$ The membrane also serves as a physical barrier between the atmospheric pressure and the vacuum inside the mass spectrometer, which greatly reduces the pumping requirements of the instrument.

Time-of-flight mass spectrometry (TOFMS) differs fundamentally from mass spectrometry techniques that use scanning instruments, such as quadrupole, ${ }^{12-14}$ ion trap, ${ }^{15-17}$ and magnetic sector $^{18}$ analyzers, in that the formation of discrete ions and the mass dispersion is accomplished in the time domain rather along a spatial axis. Because a complete spectrum is generated in each cycle, the relative intensities of ions in the source are accurately represented, even if source conditions change during the experiment. This dynamic range and rapid delivery of full mass spectra in TOFMS represent a large advantage over scanning instruments. TOFMS also has an intrinsic duty-cycle advantage that increases with the observed dynamic range in mass. ${ }^{19-22}$ Additionally, TOFMS is characterized by outstanding transmission, and, due to its simple setup, it is robust and insensitive to vibrations, which is particularly important for field applications.

Several reports have described analytical measurement of VOCs using MIMS, but only a few studies ${ }^{23-25}$ have characterized the correlation between molecular properties, membrane properties, detection limits, and response times. In addition, systematic comparisons of molecular parameters that affect the performance of silicone membrane interfaces are scarce. The purpose of this study was to describe an analytical technique that employs a membrane inlet for direct air sampling coupled to a TOFMS for the analysis of VOCs. We analyzed several aromatic and halogenated hydrocarbons to determine the factors affecting membrane performance. We also determined the de- 
tection limits and response times for representative substances.

\section{Experimental Section}

A schematic of the membrane inlet assembly, which was constructed on a standard $23 / 4$ inch Conflat flange, is shown in Figure 1. The assembly consisted of two sections (upper and lower) of the aluminum interface body, a sheet membrane, and a transfer capillary tube. Two $3 \mathrm{~mm}$ diameter holes allowed the gas sample to be flushed through the flow chamber, in which the analytes directly contacted the membrane surface. It should be apparent that larger flow chambers provide worse probe efficiencies with respect to response sensitivity and sampling frequency. ${ }^{26}$ To maximize the contact between the analyte and the membrane, the dimensions were adjusted to minimize the ratio of sample volume contacting the membrane relative to the membrane surface area. The membrane material was a $75 \mu \mathrm{m}$ thick silicone elastomer (7-4170), obtained from Dow Corning Corporation (Midland, MI, USA).

The membrane was suspended in a flat geometry between two support discs (25.0 mm OD and $4.0 \mathrm{~mm}$ ID) and was sealed with Viton o-rings mounted at both ends of the interface body. The effective membrane area was $12.6 \mathrm{~mm}^{2}$, which provided an acceptable compromise between sensitivity and quantity of air admitted to the high vacuum of the MS chamber $\left(5 \times 10^{-7}\right.$ Torr). The membrane inlet assembly was located outside the home-built TOF mass spectrometer, ${ }^{27,28} 7 \mathrm{~cm}$ away from the center of the ion source. The transport of permeated analytes from the membrane assembly to the electron ionization source of the TOF mass spectrometer occurred through a $0.5 \mathrm{~mm}$ ID deactivated fused silica tube. In order to heat and maintain the membrane assembly at a constant temperature, a cartridge heater and a K-type thermocouple were inserted into the small holes of the assembly body, and a temperature controller (Watlow, 96B0-FAAA-00-GR) was used to heat the heating element with a periodic 24 VDC pulse.

The basic membrane parameters were determined by measuring the time dependence of the ion signal from the mass spec-

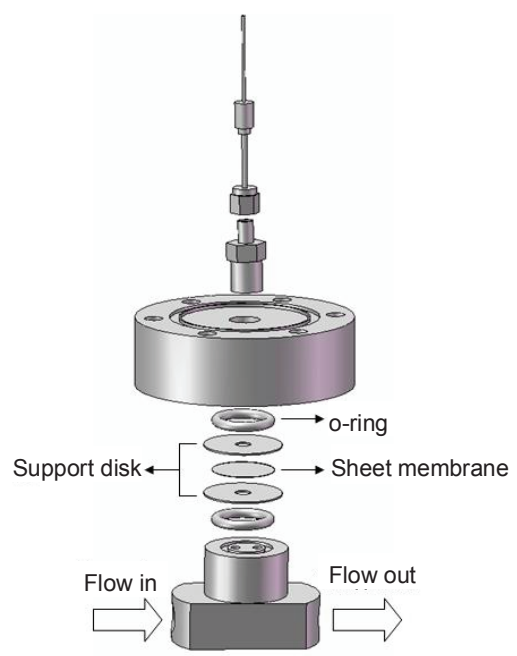

Figure 1. Schematic of the membrane inlet assembly designed for sample introduction to a TOFMS. trometer. The sample modulation was achieved with two flow channels, one connected to fresh air, and one containing the sample of low concentration organic compound in air. The flow channels were connected to a three-way magnetic valve (Cole-Parmer, A-98622-12) placed in front of the membrane inlet. When the gas sample is introduced into the membrane inlet, the signal increased rapidly after a short lag period, then apparently leveled off. The response time, taken as the time required for the signal intensity to rise from $10 \%$ to $90 \%$ of its maximum value, was determined as a function of time after the valve was opened to allow the analyte through the membrane. The ion signal was averaged by a gated integrator/boxcar averager (Stanford Research Systems), where the boxcar gate was positioned at the arrival time of an ion of interest in the TOF spectrum. Sample flow over the membrane was regulated by means of a gear pump (Cole-Parmer, A-07600-00) placed at the outlet of the membrane assembly. The typical sample flow rate was $300 \mathrm{~mL} / \mathrm{min}$.

Gaseous standard samples were generated in ppm volume concentrations by injecting microliter quantities of mixtures or individual components into a Tedlar bag prefilled with a known volume of clean dry air, then transferring aliquots into a series of additional bags. In the case of mass tuning of TOFMS, helium gas was used to dilute the mixture sample. The bags were maintained at ambient temperature $\left(25 \pm 1{ }^{\circ} \mathrm{C}\right)$ over the course of the tests. Spectrophotometric grade benzene, toluene, ethylbenzene, $o$-xylene, and halogenated benzene compounds from Sigma-Aldrich were used without further purification.

\section{Results and Discussion}

The identification of each analyte in the unknown samples required precise discrimination between ions observed in the full mass spectrum. A typical $70 \mathrm{eV}$ electron impact TOF mass spectrum obtained for the membrane introduction of a sample mixture, containing $100 \mathrm{ppm}$ toluene, $150 \mathrm{ppm}$ fluorobenzene, $50 \mathrm{ppm}$ chlorobenzene, $150 \mathrm{ppm}$ bromobenzene, and $100 \mathrm{ppm}$

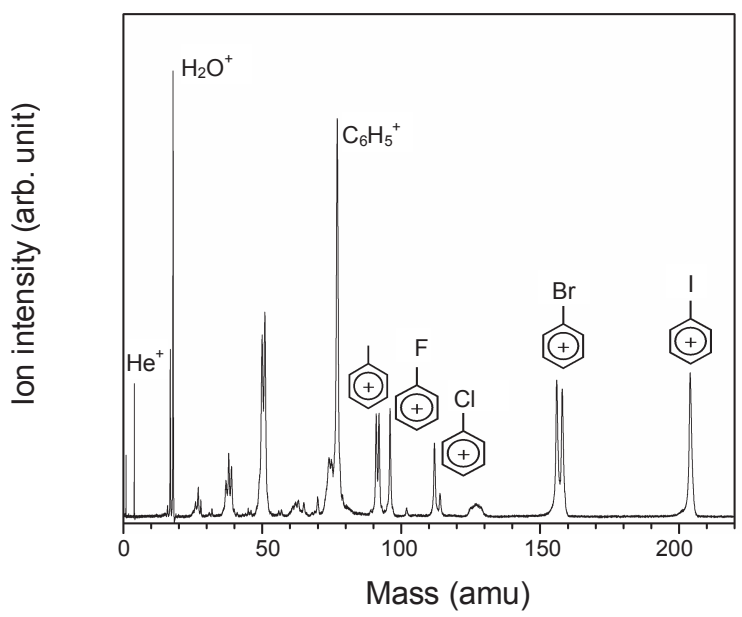

Figure 2. A typical $70 \mathrm{eV}$ electron impact time-of-flight mass spectrum of a sample containing toluene (100 ppm), fluorobenzene (150 ppm), chlorobenzene $(50 \mathrm{ppm})$, bromobenzene ( $150 \mathrm{ppm})$, and iodobenzene $(100 \mathrm{ppm})$ using the membrane inlet method. This spectrum was averaged over 500 pulses, which corresponds to $10 \mathrm{~s}$ acquisition time. 
iodobenzene in helium, is displayed in Figure 2. This spectrum is in good agreement with the mass spectrum of each component from the NIST Standard Reference Database. ${ }^{29}$ For example, toluene produced distinct ions at $\mathrm{m} / \mathrm{z} 91$ and $\mathrm{m} / \mathrm{z} 92$, with each corresponding to $\mathrm{C}_{7} \mathrm{H}_{7}{ }^{+}$and $\mathrm{C}_{7} \mathrm{H}_{8}{ }^{+}$respectively. The presence of the halogenated benzene components were also confirmed from their parent ions and isotope ratios at $m / z 96\left(\mathrm{C}_{6} \mathrm{H}_{5} \mathrm{~F}\right), \mathrm{m} / \mathrm{z}$ $112\left(\mathrm{C}_{6} \mathrm{H}_{5} \mathrm{Cl}-35\right), m / z 114\left(\mathrm{C}_{6} \mathrm{H}_{5} \mathrm{Cl}-37\right), m / z 156\left(\mathrm{C}_{6} \mathrm{H}_{5} \mathrm{Br}-79\right)$, $m / z 158\left(\mathrm{C}_{6} \mathrm{H}_{5} \mathrm{Br}-81\right)$, and $m / z 204\left(\mathrm{C}_{6} \mathrm{H}_{5} \mathrm{I}\right)$, respectively. The peak at $\mathrm{m} / z 77$ in the mass spectrum is attributed to the fragmentation and the resulting phenyl cation $\left(\mathrm{C}_{6} \mathrm{H}_{5}{ }^{+}\right)$. The peak corresponding to $\mathrm{H}_{2} \mathrm{O}^{+}(\mathrm{m} / \mathrm{z} 18)$ resulted from trace water vapor that permeated the membrane. In spite of a relatively low concentration of analytes in the mixture, the observation of these significant peaks demonstrated that the high solubility of substituted benzene molecules in the hydrophobic silicone membrane led to enrichment of the analyte after selective permeation through the membrane.

The permeation of a substance through the membrane is defined by a process that includes: (i) adsorption of the analyte to the membrane surface; (ii) diffusion through the membrane body; and (iii) release from the inner surface into the vacuum of the mass spectrometer. ${ }^{30}$ The second step of diffusion through the membrane is known to be the rate-determining process, whereas partitioning at the high-pressure surface and desorption from the low-pressure surface are considered to be instantaneous. ${ }^{31}$ Thus, the permeation process across the membrane delays the response of the mass spectrometer to the analyte present in the sample. The time-dependent signal includes a measure of the time taken to achieve a maximum signal response to a sample of fixed concentration (i.e., to achieve a steady-state composition). For real-time sampling and analysis, it is, therefore, necessary to account for the membrane response.

Figure 3 shows the detection response of benzene samples of different concentrations (50 and $500 \mathrm{ppm}$ ), which represents the convolution of transmission time through the membrane after sample introduction and the time to reach steady-state

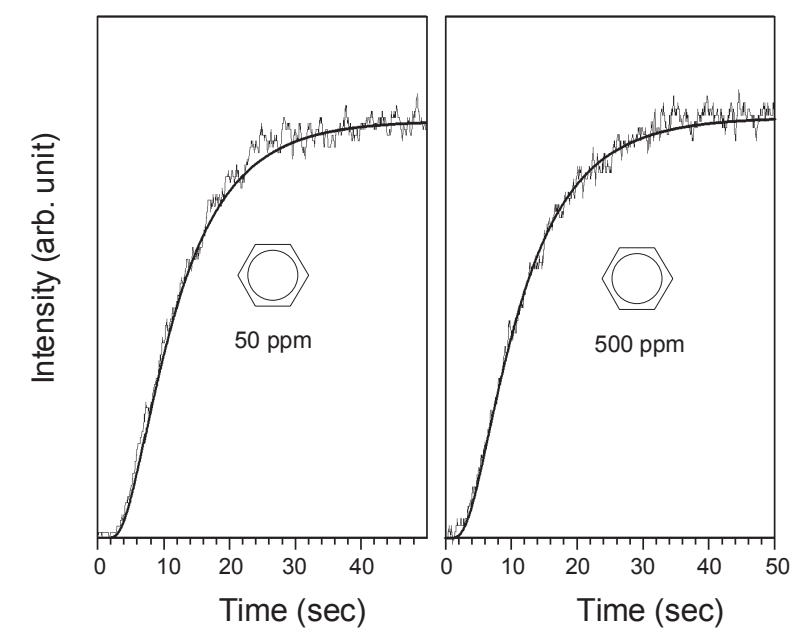

Figure 3. Response time measurements of (a) $50 \mathrm{ppm}$ and (b) $500 \mathrm{ppm}$ benzene samples obtained using a $75 \mu \mathrm{m}$ sheet membrane at room temperature. The solid lines correspond to the simulation results of nonsteady-state permeation theory (Eq. 1$)$ using the first five terms $(n=$ 1-5). The signal intensities were normalized to facilitate the comparison. detection levels at room temperature. The time dependence of the ion intensity was obtained from the gate integration of the largest peaks for benzene $(\mathrm{m} / \mathrm{z} 78)$ in the TOF spectrum. The sample modulation was controlled via an alternating valve that switched between the sample and background streams. The response time, required for the signal intensity to rise from $10 \%$ to $90 \%$ of its maximum value, was $22.9 \mathrm{~s}$, and was independent of the sample concentration, indicating that the number of analytes in the sample matrix did not affect the permeation process.

Non-steady-state permeation can be described by Fick's diffusion equation. For a step change in concentration, the mathematical solution for the time-dependent flow $J(t)$ through a sheet membrane of thickness $\ell$ is: ${ }^{32,33}$

$$
J(t)=J_{s s}\left\{1+2 \cdot \sum_{1}^{\infty}\left[(-1)^{n} \cdot \exp \left(-(n \pi / \ell)^{2} D t\right)\right]\right\}
$$

where $J_{s s}$ is the steady-state flow of an analyte in the extract stream, and $D$ is the diffusion coefficient of the analyte in the membrane polymer. The permeation process exhibits an asymptotic approach to the steady state. The best fit is presented in Figure 3, which shows permeation through a sheet membrane when each analyte concentration was instantaneously changed from 0 to a steady-state level. Each experimental curve fit well to Eq. (1) using the first five terms $(n=1-5)$. The diffusion coefficient of benzene was determined to be $D=6.6 \times 10^{-7} \mathrm{~cm}^{2} / \mathrm{s}$. This value was, however, rather low compared to our previous measurement of $D=2.2 \times 10^{-6} \mathrm{~cm}^{2} / \mathrm{s}$, observed for the $127 \mathrm{~mm}$ thick Silastic $^{\mathbb{R}}$ (polydimethylsiloxane) silicone rubber sheet membrane (Dow Corning Corp.). ${ }^{34}$ The difference in diffusion coefficients, despite the thinness of the films, probably resulted from the chemical compositions of the two membranes.

To understand how the diffusion rate is affected by the size

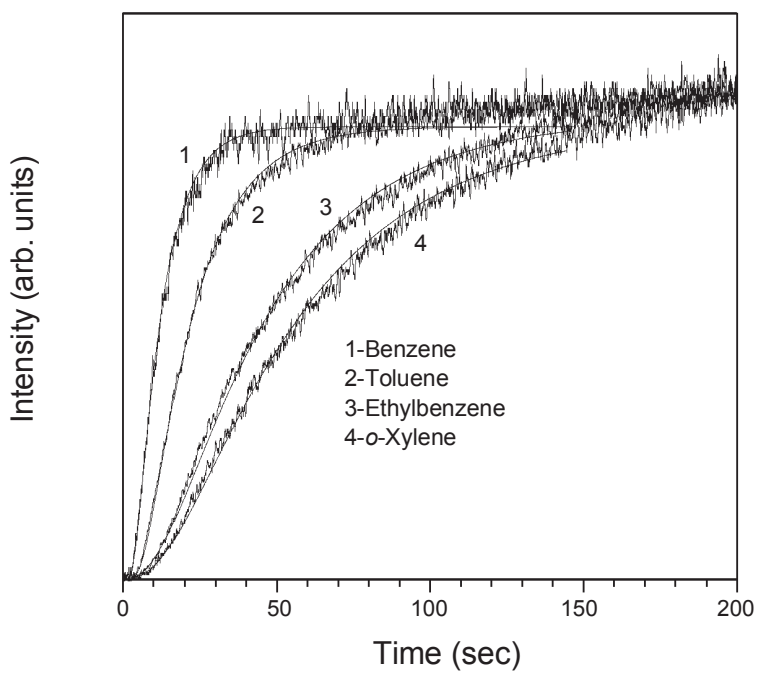

Figure 4. Response time measurements for four analytes obtained using a $75 \mu \mathrm{m}$ sheet membrane at room temperature: 1 , benzene $(22.9 \mathrm{~s}) ; 2$, toluene (37.0 s); 3, ethylbenzene ( $83.3 \mathrm{~s})$; and 4, $o$-xylene (102.5 s). The smooth lines correspond to the simulation results. The signal intensities were normalized to facilitate the comparison. 


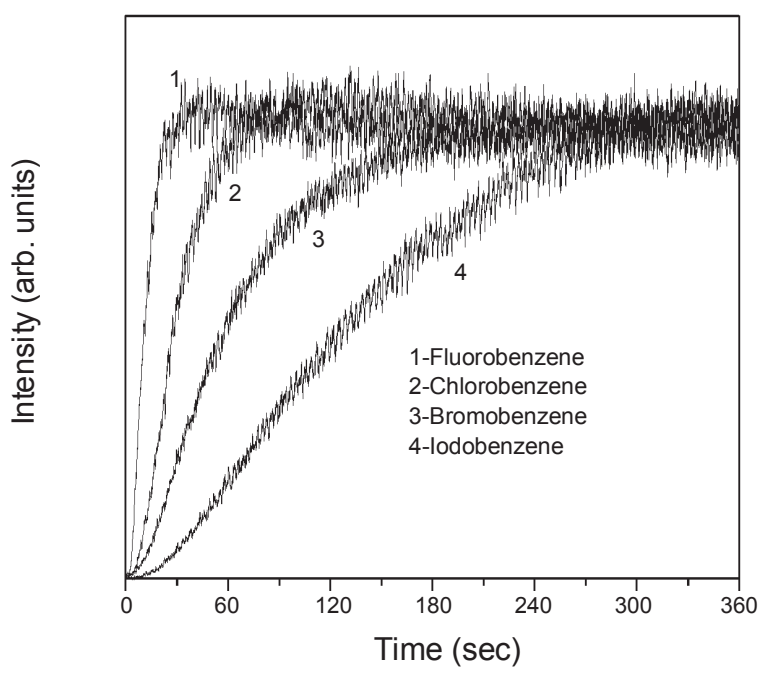

Figure 5. Normalized diffusion response curves for (1) fluorobenzene, (2) chlorobenzene, (3) bromobenzene, and (4) iodobenzene at room temperature.

and geometry of analyte molecules, we characterized the timedependent ion intensities of benzene, toluene, ethylbenzene, and $o$-xylene (500 ppm each) at room temperature (see Figure 4). The observed response times steadily decreased as the length of the aliphatic chain increased. The van der Waals interactions between the nonpolar alkyl group of the aromatic molecule and the membrane polymer strengthened for longer carbon chain lengths; thus, the diffusion through the membrane slowed. Ketola et al. obtained similar response times when analyzing VOCs in air with a $100 \mathrm{~mm}$ silicone sheet membrane. ${ }^{35}$ The longer response time of $o$-xylene compared to that of benzene could also be explained by the large critical diameter of $o$-xylene (7.4 $\AA$ compared to that of benzene, $6.7 \AA) .{ }^{36}$ Despite similarities in chemical composition, molecules with small diameters diffused faster inside the membrane matrix. These results are consistent with the fact that, if an analyte molecule interacts only weakly with the polymer or filler, the diffusion rate of the molecule depends mainly on the molecular geometry and less on the chemical properties. The measured diffusion coefficients of toluene, ethylbenzene, and $o$-xylene were determined to be $3.6 \times 10^{-7} \mathrm{~cm}^{2} / \mathrm{s}, 1.6 \times 10^{-7} \mathrm{~cm}^{2} / \mathrm{s}$, and $1.3 \times 10^{-7} \mathrm{~cm}^{2} / \mathrm{s}$, respectively.

As the analyte stream permeated the sheet membrane material, different compounds adsorbed to varying degrees and diffused at different rates. Thus, in real sampling and analysis situations, the diffusion rate determines the response time of the analysis, which in turn affects the precision of sample concentration determination during real-time measurements. Figure 5 shows the normalized response curves for fluorobenzene, chlorobenzene, bromobenzene, and iodobenzene (500 ppm each). These compounds were chosen because although they are volatile, their polarity decreases their ability to permeate the silicone membrane. ${ }^{37}$ The diffusion rate of halogenated benzene decreased with the size of halogen atom on the aromatic ring; atomic radii of $\mathrm{F}, \mathrm{Cl}, \mathrm{Br}$, and I are $0.50,1.00,1.15$, and $1.40 \AA$. Notably, the observed response curves depend more on the variation of the molecular size than on the variation of the dipole moment
Table 1. Diffusion coefficient $\left(\mathrm{cm}^{2} / \mathrm{s}\right)$ and response time $t_{10-90 \%}(\mathrm{~s})$ for selected VOCs at $25^{\circ} \mathrm{C}$

\begin{tabular}{cccr}
\hline Compounds & $\begin{array}{c}\text { Chemical } \\
\text { Formula }\end{array}$ & $D$ & $t_{10-90 \%}{ }^{a}$ \\
\hline Benzene & $\mathrm{C}_{6} \mathrm{H}_{6}$ & $6.6 \times 10^{-7}$ & 22.9 \\
Toluene & $\mathrm{C}_{7} \mathrm{H}_{8}$ & $3.6 \times 10^{-7}$ & 34.7 \\
Ethylbenzene & $\mathrm{C}_{8} \mathrm{H}_{10}$ & $1.6 \times 10^{-7}$ & 85.2 \\
$o$-Xylene & $\mathrm{C}_{8} \mathrm{H}_{10}$ & $1.3 \times 10^{-7}$ & 136.5 \\
Fluorobenzene & $\mathrm{C}_{6} \mathrm{H}_{5} \mathrm{~F}$ & $6.2 \times 10^{-7}$ & 23.2 \\
Chlorobenzene & $\mathrm{C}_{6} \mathrm{H}_{5} \mathrm{Cl}$ & $2.5 \times 10^{-7}$ & 54.5 \\
Bromobenzene & $\mathrm{C}_{6} \mathrm{H}_{5} \mathrm{Br}$ & $1.3 \times 10^{-7}$ & 108.5 \\
Iodobenzene & $\mathrm{C}_{6} \mathrm{H}_{5} \mathrm{I}$ & $5.4 \times 10^{-8}$ & 187.6 \\
Methanol & $\mathrm{CH}_{3} \mathrm{OH}$ & $3.4 \times 10^{-7}$ & 40.0 \\
Ethanol & $\mathrm{C}_{2} \mathrm{H}_{5} \mathrm{OH}$ & $4.7 \times 10^{-7}$ & 28.3 \\
2-Propanol & $\mathrm{C}_{3} \mathrm{H}_{7} \mathrm{OH}$ & $6.8 \times 10^{-7}$ & 20.0 \\
1-Butanol & $\mathrm{C}_{4} \mathrm{H}_{9} \mathrm{OH}$ & $4.0 \times 10^{-7}$ & 23.65 \\
\hline
\end{tabular}

${ }^{a}$ The response times were not concentration-dependent.

(fluorobenzene, 1.60 D; chlorobenzene, 1.69 D; bromobenzene, $1.70 \mathrm{D}$; iodobenzene, $1.70 \mathrm{D}) .^{38}$ These results demonstrate that it is the size of substituents rather than the polarity of the analyte that influences the diffusion rate. The slow diffusion rate of iodobenzene compared to benzene and aliphatic iodoalkanes presumably arose from the fact that iodobenzene molecules stuck to the surface of the membrane and did not evaporate as readily into the vacuum.

The diffusion coefficients and response times required for the signal intensity to rise from $10 \%$ to $90 \%$ of its maximum value $\left(t_{10-90 \%}\right)$ are summarized in Table 1 for all samples investigated. Measurement errors arose from (i) adsorption of organic compounds to the vacuum chamber walls as they issued from the membrane, and (ii) the time required for the sample to travel from the sampling cylinder to the membrane surface $(\leq 1 \mathrm{~s})$. Both of these errors would result in smaller measured diffusion coefficients for molecules containing higher numbers of carbon atoms. The aromatic compounds benzene $(22.9 \mathrm{~s})$, toluene $(34.7 \mathrm{~s})$, ethylbenzene $(85.2 \mathrm{~s})$, and $o$-xylene $(136.5 \mathrm{~s})$ gave slower responses than iodomethane (187.6 s), primarily due to their molecular size. Finally, the $D$ and $t_{10-90 \%}$ values obtained here are in good agreement with previously reported results. ${ }^{14,26,39}$

The response times for aromatic compounds fell steadily as the length of the carbon chain increased. Regardless of polarity, rapid diffusion was observed for compounds with the weakest membrane interactions. The polydimethylsiloxane membrane used in the current experiment is a hydrophobic polymer that interacts most strongly with compounds bearing methyl or alkyl groups via van der Waals interactions. The strength of interaction was proportional to the number of methyl groups or to the length of the alkyl chain of the analyte, and stronger interactions increased diffusion through the membrane. Furthermore, the response times of halogenated compounds notably increased from fluorobenzene to iodobenzene, demonstrating that the analyte-polymer interaction was more strongly affected by the analyte size and total number of substituents (halogen atoms) than by the analyte's structure or polarity. 


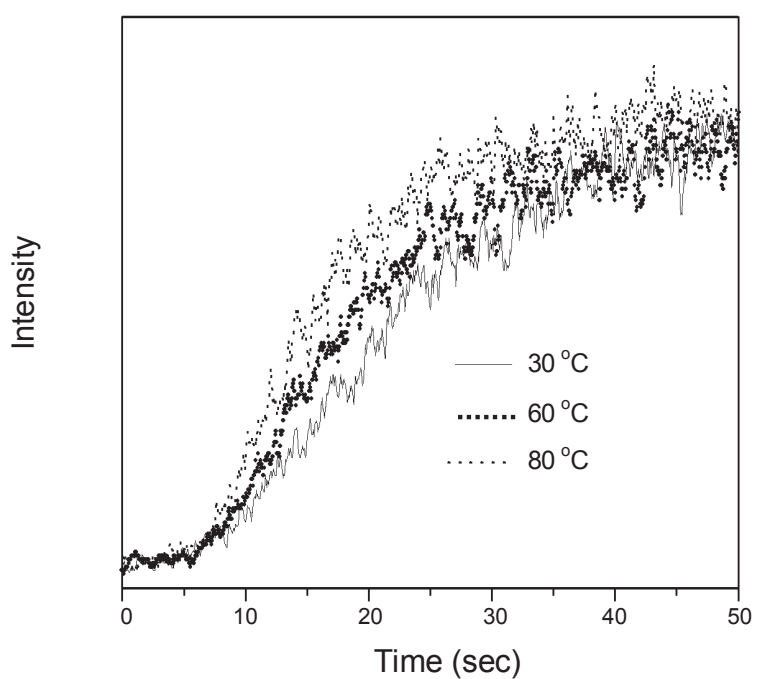

Figure 6. Response time measurements of $50 \mathrm{ppm}$ benzene samples at different membrane temperature.

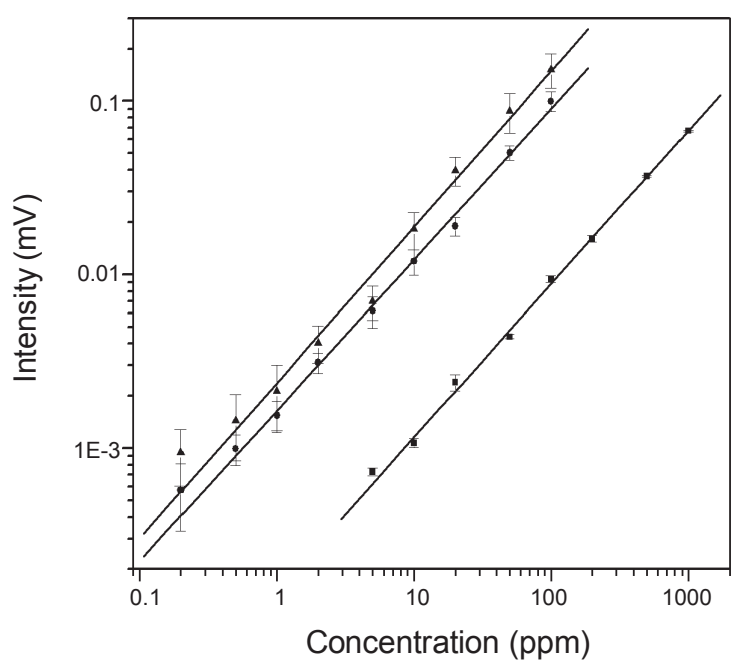

Figure 7. Results of a typical calibration measurement of benzene (•), ethylbenzene ( $\mathbf{\Delta}$ ), and 2-propanol ( $\bullet$ ) in air using the MIMS.

The effect of temperature on membrane introduction during environmental monitoring was evaluated by measuring the instrument response time as a function of membrane temperature. Figure 6 shows the typical response times of a $50 \mathrm{ppm}$ benzene sample measured at three temperatures: 30,60 , and $80^{\circ} \mathrm{C}$. There appeared to be a slight decrease in response time with increasing temperature, in agreement with the results of Maden et al. ${ }^{14}$ The result clearly showed that increasing the temperature significantly improved the response time. However, at higher temperatures, additional air molecules were admitted to the mass spectrometer, producing an erratic response that may be detrimental to the accuracy and precision required for quantitative analysis. Experience with this membrane interface suggests $50{ }^{\circ} \mathrm{C}$ is optimal for nearly all applications.

In addition to the diffusion rate, the sensitivity of the membrane inlet system was also an important factor for the trace analysis. The detection limits and linearity ranges of the mem- brane inlet system were measured by examining samples of air containing varying concentrations of benzene, ethylbenzene, and 2-propanol. By considering the response time of each sample, peak intensity was measured at the time of maximum permeation after the gas sample is introduced into the membrane inlet: benzene (30 s); ethylbenzene (90 s); 2-propanol (25 s). This allowed us to estimate the sensitivity that could be obtained by use of the membrane inlet. Figure 7 shows the relationship between sample concentration and peak intensity for benzene $(\mathrm{m} / \mathrm{z} 78)$, ethylbenzene $(\mathrm{m} / \mathrm{z} 106)$, and 2-propanol $(\mathrm{m} / \mathrm{z} 45)$ for each mass spectrum. Each calibration point represents the average peak intensity obtained by sampling each concentration 3-5 times. The data fell approximately on a straight line, indicating reasonable linearity and instrumental stability. Error bars indicate one standard deviation from the average intensity. The linear dynamic range for benzene, ethylbenzene (0.2 - $100 \mathrm{ppm})$, and 2-propanol (4 - $1000 \mathrm{ppm})$ were typically around three orders of magnitude. These wide dynamic ranges of the membrane inlet method are in good agreement with the dynamic ranges previously reported for other VOCs. ${ }^{35}$

The permeability of an analyte depends on the product of the solubility and diffusion coefficients, whereas the diffusion rate depends only on the diffusion coefficient. In a recent characterization of a silicone membrane using a proton transfer reaction mass spectrometer, Märk and coworkers found that, for a homologous series of nonpolar compounds, the solubility increased and the diffusion rate decreased as the length of the carbon chain increased. ${ }^{40}$ The lower limits for detection of benzene, ethylbenzene, and 2-propanol in the present experiment were approximately $0.2 \mathrm{ppm}, 0.1 \mathrm{ppm}$, and $3.0 \mathrm{ppm}$. The low detection limit for simple aromatic compounds suggests that nonpolar compounds may have a higher permeability through the membrane. Given that 2-propanol has a larger diffusion coefficient and aromatic compounds have better silicone permeability (the product of the solubility and the diffusion coefficient), benzene and ethylbenzene must be significantly more soluble in the silicone membrane. Similarly, analytes with longer alkyl chains have been shown to result in lower detection limits because the increase in solubility is larger than the diffusion coefficient decrease for lengthier alkyl chains. ${ }^{40}$ This implies that permeability is largely determined by the solubility of the analytes in the membrane.

\section{Conclusion}

In the present study, we comprehensively examined the transient diffusion characteristics that affect mass transport of analytes through a $75 \mu \mathrm{m}$ silicone sheet membrane by TOFMS detection of VOCs in air samples. During evaluation of the inlet assembly performance, the time-dependent diffusion characteristics, which fit well to a non-steady-state flow equation, revealed that the diffusion rate decreased with increasing size of the molecule and carbon chain length of the analyte. Representative aromatic hydrocarbons had detection limits at the sub-ppm level, whereas polar alcohol compounds had higher detection limits due to the hydrophobic nature of the silicone membrane. The integration of both the sample concentrating capabilities of membrane inlet techniques and the prompt res- 
ponse and wide dynamic range of TOFMS, demonstrated here, will provide a powerful technique for field detection of airborne samples.

Acknowledgments. This work was supported by Wonkwang University in 2008.

\section{References}

1. Mitra, S.; Kebbekus, B. Environmental Chemical Analysis; Chapman and Hall/CRC: Boca Raton, Florida, 1998.

2. Melita, L.; Popescu, M. J. Membr. Sci. 2008, 312, 157.

3. Hendren, Z. D.; Brant, J.; Wiesner, M. R. J. Membr. Sci. 2009, 331,1 .

4. Jönsson, J. A. 2003, 57, S/317.

5. Johnson, R. C.; Cooks, R. G.; Allen, T. M.; Cisper, M. E.; Hemberger, P. H. Mass Spectrom. Rev. 2000, 19, 1.

6. Ketola, R. A.; Kotiaho, T.; Cisper, M. E.; Allen, T. M. J. Mass Spectrom. 2002, 37, 457.

7. Viktorova, O. S.; Kogan, V. T.; Manninen, S. A.; Kotiaho, T.; Ketola, R. A.; Dubenskii, B. M.; Parinov, S. P.; Smirnov, O. V.J. Am. Soc. Mass Spectrom. 2004, 15, 823.

8. Janes, D. W.; Durning, C. J.; van Pel, D. M.; Lynch, M. S.; Gill, C. G.; Krogh, E. T. J. Membr. Sci. 2008, 325, 81.

9. Schlueter, M.; Gentz, T. J. Am. Soc. Mass Spectrom. 2008, 19, 1395.

10. Frandsen, H.; Janfelt, C.; Lauritsen, F. R. Rapid Commun. Mass Spectrom. 2007, 21, 1574.

11. Oser, H.; Coggiola, M. J.; Young, S. E.; Crosley, D. R.; Hafer, V.; Grist, G. Chemosphere 2007, 67, 1701.

12. Mendes, M. A.; Eberlin, M. N. Analyst 2000, 125, 21.

13. Sysoev, A. A.; Ketola, R. A.; Mattila, I.; Tarkiainen, V.; Kotiaho, T. Int. J. Mass Spectrom. 2001, 212, 205.

14. Maden, A. J.; Hayward, M. J. Anal. Chem. 1996, 68, 1805.

15. Allen, T. M.; Falconer, T. M.; Cisper, M. E.; Borgerding, A. J.; Wilkerson, C. W., Jr. Anal. Chem. 2001, 73, 4830.

16. Moxom, J.; Reilly, P. T. A.; Whitten, W. B.; Ramsey, J. M. Anal. Chem. 2003, 75, 3739.

17. Yoon, T. O.; Choi, C. M.; Kim, H. J.; Kim, N. J. Bull. Korean Chem. Soc. 2007, 28, 619.

18. Sinha, M. P.; Tomassian, A. D. Rev. Sci. Instrum. 1991, 62, 2618.
19. Wiley, W. C.; McLaren, I. H. Rev. Sci. Instrum. 1955, 26, 1150.

20. White, A. J.; Blamire, M. G.; Corlett, C. A.; Griffiths, B. W.; Martin, D. M.; Spencer, S. B.; Mullock, S. J. Rev. Sci. Instrum. 1998, 69, 565.

21. Bae, Y. J.; Yoon, S. H.; Moon, J. H.; Kim, M. S. Bull. Korean Chem. Soc. 2010, 31, 92.

22. Song, K.; Cha, H.; Kim, D.; Min, K. Bull. Korean Chem. Soc. 2004, 25,101 .

23. Alexander, M. A.; Boscaini, E.; Lindinger, W.; Märk, T. D. Int. J. Mass Spectrom. 2003, 223-224, 763.

24. Hansen, K. F.; Gylling, S.; Lauritsen, F. R. Int. J. Mass Spectrom. 1996, 152, 143.

25. Miranda, L. D.; Short, R. T.; van Amerom, F. H. W.; Bell, R. J.; Byrne, R. H. J. Membr. Sci. in press.

26. Dongré, A. R.; Hayward, M. J. Anal. Chim. Acta 1996, 327, 1.

27. Kim, T.-K.; Jung, K.-H.; Yoo, S.-K.; Jung, K.-W. Bull. Korean Chem. Soc. 2005, 26, 303.

28. Jung, K.-W.; Choi, S. S.; Jung, K.-H. Rev. Sci. Instrum. 1991, 62, 2125.

29. NIST Standard Reference Database 69; November 1998 Release: NIST Chemistry WebBook.

30. Watson, J. M.; Payne, P.A. J. Membr. Sci. 1990, 49, 171.

31. Tsai, G.-J.; Austin, G. D.; Syu, M. J.; Tsao, G. T.; Hayward, M. J.; Kotiaho, T.; Cooks, T. G. Anal. Chem. 1991, 63, 2460.

32. Pasternak, R. A.; Schimscheimer, J. F.; Heller, J. J. Polym. Sci. 1970, 8, 467.

33. Overney, F. L.; Enke, C. G. J. Am. Soc. Mass Spectrom. 1996, 7 , 93.

34. Oh, K.-S.; Koo, Y.-M.; Jung, K.-W. Int. J. Mass Spectrom. 2006, 253,65 .

35. Ketola, R. A.; Ojala, M.; Sorsa, H.; Kotiaho, T.; Kostiainen, R. Anal. Chim. Acta 1997, 349, 359.

36. Sigma Aldrich Technical Information Bulletin: Mineral adsorbents, filter agents, and drying agents, http://www.sigmaaldrich.com/ chemistry/aldrich-chemistry/tech-bulletins/al-143.html

37. Lauritsen, F. R.; Bohatka, S.; Degn, H. Rapid Commun. Mass Spectrom. 1990, 4, 401

38. Lide, D. R. CRC Handbook of Chemistry and Physics, 81 th ed.; CRC Press: London, 2000.

39. LaPack, M. A.; Tou, J. C.; Enke, C. G. Anal. Chem. 1990, 62, 1265.

40. Boscaini, E.; Alexander, M. L.; Prazeller, P.; Märk, T. D. Int. J. Mass Spectrom. 2004, 239, 179. 